\title{
ATUAÇÃO DO ENFERMEIRO NO ATENDIMENTO AO ADOLESCENTE QUE UTILIZA INDEVIDAMENTE ANABOLIZANTE E SUPLEMENTO
}

\author{
Samara Serpa Ferreira ${ }^{1}$ \\ Márcia Vanessa dos Santos ${ }^{2}$ \\ Daniela Freitas da Silva ${ }^{3}$ \\ Danielle Alice Teodoro dos Reis ${ }^{4}$ \\ Kellen Cristina Amin da Silva ${ }^{5}$ \\ Lucélia Pires Vieira de Paula ${ }^{6}$ \\ Antônio Carlos Prianti Junior ${ }^{7}$ \\ Sônia Maria Filipini ${ }^{8}$ \\ Isabella Bueno Rossetti ${ }^{9}$
}

\begin{abstract}
Resumo: A adolescência é caracterizada pela formação e fixação da identidade do indivíduo na sociedade. Nesse período de vulnerabilidade, o esteriotipo de corpos perfeitos divulgados pela mídia é transformado em um objetivo a ser alcançado com rapidez, utilizando indevidamente de anabolizantes e suplementos. $O$ enfermeiro deve conhecer e saber orientar este grupo perante ao uso dessas substâncias. A pesquisa inicial resultou em 229 resultados, sendo utilizados outros estudos encontrados que abordavam o assunto. Foram utilizados como critérios de exclusão resultados repetidos e estudos sem relação com o tema proposto. Concluímos que os estudos sobre esse tema é escasso, pois foram encontradas poucas evidências e estas não focam na atuação do enfermeiro, impossibilitando a construção sólida de uma base cientifica para o profissional basear seus cuidados.
\end{abstract}

Palavras-chave: Enfermeiro; Adolescência; Anabolizante; Suplemento.

\footnotetext{
${ }^{1}$ Enfermagem/Anhanguera Educacional, Brasil. E-mail: ferreira.saah@gmail.com.

2 Enfermagem/Anhanguera Educacional, Brasil. E-mail: mvansantos@gmail.com.

3 Enfermagem/Anhanguera Educacional, Brasil. E-mail: dani.freitassilva7@hotmail.com.

4 Enfermagem/Anhanguera Educacional, Brasil. E-mail: dani-atr@hotmail.com.

5 Enfermagem/Anhanguera Educacional, Brasil. E-mail: kellen.silva@santosdumonthospital.com.br.

${ }^{6}$ Enfermagem/Anhanguera Educacional, Brasil. E-mail: luceliadejesuseucaristico@yahoo.com.br.

7 Anhanguera Educacional, Brasil. E-mail: antonio_junior2@aedu.com.

8 Anhanguera Educacional, Brasil. E-mail: sonia.filipini@aedu.com.

${ }^{9}$ Anhanguera Educacional, Brasil. E-mail: isabelarossetti@aedu.com.
} 